\title{
The associations of parity and maternal age with small-for-gestational-age, preterm, and neonatal and infant mortality: a meta-analysis
}

\author{
Naoko Kozuki ${ }^{1}$, Anne CC Lee ${ }^{1,2}$, Mariangela F Silveira ${ }^{3}$, Ayesha Sania ${ }^{4}$, Joshua P Vogel ${ }^{5,6}$, Linda Adair ${ }^{7}$, \\ Fernando Barros ${ }^{3,8}$, Laura E Caulfield ${ }^{1}$, Parul Christian ${ }^{1}$, Wafaie Fawzi ${ }^{9}$, Jean Humphrey ${ }^{1,10}$, Lieven Huybregts ${ }^{11,12}$, \\ Aroonsri Mongkolchati ${ }^{13}$, Robert Ntozini ${ }^{10}$, David Osrin ${ }^{14}$, Dominique Roberfroid ${ }^{12}$, James Tielsch ${ }^{1}$, Anjana Vaidya ${ }^{14}$, \\ Robert E Black', Joanne Katz ${ }^{\text {* }}$, \\ Child Health Epidemiology Reference Group (CHERG) Small-for-Gestational-Age-Preterm Birth Working Group ${ }^{1}$
}

\begin{abstract}
Background: Previous studies have reported on adverse neonatal outcomes associated with parity and maternal age. Many of these studies have relied on cross-sectional data, from which drawing causal inference is complex. We explore the associations between parity/maternal age and adverse neonatal outcomes using data from cohort studies conducted in low- and middle-income countries (LMIC).

Methods: Data from 14 cohort studies were included. Parity (nulliparous, parity 1-2, parity $\geq 3$ ) and maternal age ( $<18$ years, 18- $<35$ years, $\geq 35$ years) categories were matched with each other to create exposure categories, with those who are parity $1-2$ and age 18-<35 years as the reference. Outcomes included small-for-gestational-age (SGA), preterm, neonatal and infant mortality. Adjusted odds ratios (aOR) were calculated per study and meta-analyzed.
\end{abstract}

Results: Nulliparous, age $<18$ year women, compared with women who were parity 1-2 and age $18-<35$ years had the highest odds of SGA (pooled adjusted OR: 1.80), preterm (pooled aOR: 1.52), neonatal mortality (pooled aOR: 2.07), and infant mortality (pooled aOR: 1.49). Increased odds were also noted for SGA and neonatal mortality for nulliparous/age 18-<35 years, preterm, neonatal, and infant mortality for parity $\geq 3$ /age $18-<35$ years, and preterm and neonatal mortality for parity $\geq 3 / \geq 35$ years.

Conclusions: Nulliparous women $<18$ years of age have the highest odds of adverse neonatal outcomes. Family planning has traditionally been the least successful in addressing young age as a risk factor; a renewed focus must be placed on finding effective interventions that delay age at first birth. Higher odds of adverse outcomes are also seen among parity $\geq 3$ / age $\geq 35$ mothers, suggesting that reproductive health interventions need to address the entirety of a woman's reproductive period.

Funding: Funding was provided by the Bill \& Melinda Gates Foundation (810-2054) by a grant to the US Fund for UNICEF to support the activities of the Child Health Epidemiology Reference Group.

\section{Introduction}

Parity and maternal age have been shown to increase the risk of adverse neonatal outcomes, such as intrauterine growth restriction (IUGR), prematurity, and mortality [1-5]. Nulliparity may confer risk through complications

\footnotetext{
* Correspondence: jkatz@jhsph.edu

'Department of International Health, Johns Hopkins Bloomberg School of

Public Health, 615 N. Wolfe St., Baltimore, MD 21205, USA

Full list of author information is available at the end of the article
}

during childbirth such as obstructed labor [6], whereas high parity has been linked to increased risk of hypertension, placenta previa, and uterine rupture [4]. Several studies have hypothesized that in young mothers, maternal-fetal competition for nutrients and/or the mother's incomplete physical growth might contribute to adverse neonatal outcomes [7]. Older women experience an increase in the incidence of congenital abnormalities as well as maternal morbidities such as hypertension and

\section{Biomed Central}


gestational diabetes $[8,9]$. However, some literature has suggested that controlling for socioeconomic status heavily attenuates or eliminates associations of adolescence and of high parity with adverse outcomes [10,11].

Despite the abundance of existing literature on parity and maternal age as risk factors for adverse neonatal outcomes, methodological issues in many studies make it difficult to draw strong conclusions. Several studies have utilized cross-sectional data, often Demographic and Health Surveys (DHS) [12-14]. Cross-sectional studies cannot assess causality easily. Furthermore, information recorded at the time of interview, i.e. confounders like socioeconomic factors, may fail to reflect the true condition at the time of pregnancy and delivery. In addition, the quality of relevant variables may be poor in surveys. For example, gestational age data dependent on maternal recall are expected to be less accurate than data from prospective cohort studies where women of reproductive age are closely tracked and/or estimated gestational age is corroborated through clinical assessment.

Studies have also failed to examine the potential confounding effects of other reproductive health-related variables, socioeconomic status, or maternal nutrition. One systematic review found an association between nulliparity and SGA, but not prematurity; however, it failed to limit the studies included in the meta-analysis to those that controlled for maternal age [4]. Furthermore, the studies that do control for these confounders often fail to indicate whether the adjustment may have altered the associations [3], preventing us from understanding the biological or confounding mechanisms linking parity and maternal age to poor outcomes.

Categorizations and definitions of risk factors and outcomes described in the present literature have differed across studies. For example, the low-risk reference category for parity varies substantially across studies (i.e. birth orders 2-3 [4], 2-4 [15], and 2-5 [16]). Definitions of young age also differ, with cut-offs ranging from 16 to 18 [2], and some authors have evaluated age since first menarche. Definitions of outcomes also vary. Various proxies for IUGR have been used $[17,18]$, the most common being small-for-gestational-age (SGA) defined as birthweight below the $10^{\text {th }}$ percentile of a gender-specific reference distribution of birthweight at a particular gestational age. Such variety in exposure and outcome definitions makes it difficult to compare results across studies.

An objective of the family planning section of this supplement is to derive the best estimate of associations between reproductive health-related maternal risk factors and adverse neonatal outcomes to include in the Lives Saved Tool (LiST). LiST is a software product that produces evidence-based estimates of changes in maternal and child mortality if a health intervention is scaled up in a particular country [19]. We used original data from prospective cohort studies to examine parity and maternal age as exposures for adverse neonatal and infant outcomes. Our aim was to apply standardized categorizations and definitions for the exposure and outcome variables across studies in order to obtain best estimates. We controlled for available confounders such as socioeconomic status and maternal nutrition to examine their effect on associations. The findings will help us understand if and how family planning programs may impact neonatal and infant survival, as well as better evaluate the potential mechanisms linking these risk factors to adverse outcomes.

\section{Methods}

Our general approach was to identify individual prospective birth cohorts for which we conducted a standardized set of analyses, and then to meta-analyze the individual study associations. First, population-based, prospective cohort studies from LMIC with information on parity and maternal age, newborn birthweight (collected within the first 72 hours), and gestational age were identified from studies extracted for a separate analysis [Table 1]. Briefly, the separate analysis sought to estimate neonatal and infant mortality risk of SGA and preterm births. Datasets were identified through a literature review conducted in September 2009. We searched Medline and WHO regional databases to identify birth cohorts that contained relevant data including gestational age, birthweight, and vital status on newborns up to at least one month of life. Investigators of those studies were contacted and invited to contribute data or conduct analysis using a standardized analysis plan. Additional birth cohorts from ongoing or recently completed maternal-health studies were identified by word-of-mouth by members of the Child Health Epidemiology Reference Group (CHERG) SGA-Preterm Birth working group. More details are available in a separate publication [20]. Fourteen datasets were identified [21-35].

\section{Independent variable}

For each dataset, nine risk categories were created, matching the three parity categories (nulliparity, parity 1 2 as reference parity, parity $\geq 3$ ) and three maternal age categories $(<18$ years, $18-<35$ years as reference age, $\geq 35$ years) [Table 2]. These categories were chosen because DHS uses these cut-offs to identify "high-risk fertility behavior" [36,37]. We defined parity as the number of live births before the current pregnancy. The nine risk categories are mutually exclusive. Throughout the paper, we will use the denotation of "parity category/age category" (i.e. nulliparous / age $<18$ ) to indicate categories of women who belong to both the indicated parity category and age category. 
Table 1 Description of studies included in the analysis

\begin{tabular}{|c|c|c|c|c|c|c|c|}
\hline & Country & $\mathbf{N}$ & Type of study & Setting & $\begin{array}{c}\text { Facility } \\
\text { delivery } \\
\text { rate }\end{array}$ & $\begin{array}{l}\% \\
\text { LBW }\end{array}$ & $\begin{array}{l}\text { Method of gestational age } \\
\text { measurement }\end{array}$ \\
\hline \multirow[t]{6}{*}{ Asia } & $\begin{array}{l}\text { India (2000) } \\
\quad[25]\end{array}$ & 12,936 & $\begin{array}{l}\text { RCT of newborn Vitamin A } \\
\text { supplementation }\end{array}$ & Rural & 63 & 33 & LMP \\
\hline & $\begin{array}{l}\text { Nepal (1999) } \\
{[26]}\end{array}$ & 4,130 & $\begin{array}{l}\text { Cluster RCT of multiple micronutrient } \\
\text { supplementation }\end{array}$ & Rural & 6 & 39 & LMP \\
\hline & $\begin{array}{l}\text { Nepal (2003) } \\
{[28]}\end{array}$ & 1,106 & $\begin{array}{l}\text { RCT of antenatal micronutrient } \\
\text { supplementation }\end{array}$ & $\begin{array}{l}\text { Peri- } \\
\text { urban }\end{array}$ & 53 & 22 & Ultrasound \\
\hline & $\begin{array}{c}\text { Nepal (2004) } \\
{[27]}\end{array}$ & 23,662 & $\begin{array}{l}\text { Cluster RCT of newborn skin-umbilical } \\
\text { cord cleansing with chlorhexidine }\end{array}$ & Rural & 10 & 30 & LMP \\
\hline & $\begin{array}{l}\text { Philippines } \\
\text { (1983)[29] }\end{array}$ & 3,080 & $\begin{array}{l}\text { Longitudinal Health-nutritional survey of } \\
\text { infant feeding patterns }\end{array}$ & Urban & 34 & 11 & LMP, Ballard \\
\hline & $\begin{array}{l}\text { Thai (2001) } \\
\text { [30] }\end{array}$ & 4,245 & Prospective follow-up of birth cohort & Urban & 99 & 8 & $\begin{array}{l}\text { Best obstetric estimate (LMP, } \\
\text { ultrasound or neonatal assessment) }\end{array}$ \\
\hline \multirow[t]{4}{*}{ Africa } & $\begin{array}{c}\text { Burkina Faso } \\
\text { (2004)[31] }\end{array}$ & 1,373 & $\begin{array}{l}\text { RCT of multiple micronutrient } \\
\text { supplementation }\end{array}$ & Rural & 77 & 17 & Ultrasound at recruitment \\
\hline & $\begin{array}{l}\text { Burkina Faso } \\
\text { (2006)[34] }\end{array}$ & 1,316 & $\begin{array}{l}\text { RCT of maternal fortified food } \\
\text { supplementation }\end{array}$ & Rural & 84 & 16 & Ultrasound at recruitment \\
\hline & $\begin{array}{l}\text { Tanzania } \\
(2001)[32]\end{array}$ & 7,752 & $\begin{array}{l}\text { RCT of maternal multiple micronutrient } \\
\text { supplementation }\end{array}$ & Urban & 98 & 10 & LMP \\
\hline & $\begin{array}{l}\text { Zimbabwe } \\
(1997)[33,35]\end{array}$ & 14,110 & $\begin{array}{c}\text { RCT of postpartum maternal and neonatal } \\
\text { Vitamin A supplementation }\end{array}$ & Urban & 88 & 14 & Capurro \\
\hline \multirow[t]{4}{*}{ Americas } & $\begin{array}{l}\text { Brazil (1982) } \\
\quad[21]\end{array}$ & 5,914 & Prospective cohort study & Urban & 100 & 7 & LMP \\
\hline & $\begin{array}{l}\text { Brazil (1993) } \\
\quad[22]\end{array}$ & 5,279 & Prospective cohort study & Urban & 100 & 9 & LMP, Dubowitz \\
\hline & $\begin{array}{l}\text { Brazil (2004) } \\
\quad[23]\end{array}$ & 4,287 & Prospective cohort study & Urban & 100 & 11 & LMP, Dubowitz, ultrasound if available \\
\hline & $\begin{array}{l}\text { Peru (1995) } \\
\quad[24]\end{array}$ & 978 & RCT of maternal zinc supplementation & Urban & 100 & 4 & LMP, clinical indications \\
\hline
\end{tabular}

$\mathrm{RCT}=$ randomized controlled trial

LMP = last menstrual period

LBW $=$ low birthweight

Women in a risk category were compared to those in the reference category (parity 1-2/age 18-<35), creating a binary exposure variable for each risk category. The prevalence in each risk category was calculated separately by study. We only conducted analyses on a risk category if at least half of the studies (seven out of 14) reported having a prevalence of $5 \%$ or more in that category. Calculating associations for risk categories with extremely low prevalence would produce unstable estimates with wide uncertainty.

\section{Outcome variables}

A common SGA reference distribution and preterm definition were used across all studies. We defined SGA

Table 2 Parity/age categories and their median and range of prevalence across included cohort studies

\begin{tabular}{|c|c|c|c|}
\hline & Nulliparous & Parity 1-2 (reference) & Parity $\geq 3$ \\
\hline Age $<18$ & $\begin{array}{r}\text { Median: } 7.37 \% \\
\text { Range: } 0.13-12.74 \% \\
\mathrm{~N}^{*}=9\end{array}$ & $\begin{array}{r}\text { Median: } 0.76 \% \\
\text { Range: } 0.01-2.65 \% \\
\mathrm{~N}=0\end{array}$ & $\begin{array}{r}\text { Median: } 0.00 \\
\text { Range: } 0.00-0.22 \% \\
\mathrm{~N}=0\end{array}$ \\
\hline $\begin{array}{r}\text { Age } 18-<35 \\
\text { (reference) }\end{array}$ & $\begin{array}{r}\text { Median: } 28.27 \% \\
\text { Range: } 1.20-43.72 \% \\
\mathrm{~N}=14\end{array}$ & $\begin{array}{r}\text { Median: } 39.93 \% \\
\text { Range: } 33.28-51.50 \% \\
\mathrm{~N}=14 \\
\end{array}$ & $\begin{array}{r}\text { Median: } 13.42 \% \\
\text { Range: } 7.17-35.64 \% \\
N=14\end{array}$ \\
\hline Age $\geq 35$ & $\begin{array}{r}\text { Median: } 0.08 \% \\
\text { Range: } 0.00-1.54 \% \\
\mathrm{~N}=0\end{array}$ & $\begin{array}{r}\text { Median: } 0.71 \% \\
\text { Range: } 0.00-6.30 \% \\
\mathrm{~N}=2\end{array}$ & $\begin{array}{r}\text { Median: } 5.52 \% \\
\text { Range: } 0.17-9.19 \% \\
\mathrm{~N}=7\end{array}$ \\
\hline
\end{tabular}

Median and Range are described across all 14 cohort studies.

*The Ns indicated reflects how many studies out of the 14 included studies have $\geq 5 \%$ prevalence in that category. 
as below the $10^{\text {th }}$ percentile of the U.S. 1991 reference distribution described by Alexander and colleagues [38]. We used this reference distribution, as this is the most commonly used and cited, allowing for comparability with other studies. Preterm was defined as below 37 completed weeks of gestation. The method of gestational age measurement for each study is listed in Table 1. We also created the composite outcome variables termappropriate for-gestational-age (AGA), term-SGA, preterm-AGA, and preterm-SGA, with term-AGA as the reference. When mortality information was available, neonatal mortality was defined as death within 28 days, and infant mortality as death within 365 days. All newborns were included in the analysis examining the outcomes of preterm, neonatal, and infant mortality, even if the child did not have a weight available to examine SGA as an outcome.

\section{Data analysis}

Datasets were first analyzed individually. Ten of the 14 cohort study datasets were available to the primary author to analyze; the remaining four datasets were analyzed by collaborators using a standardized template. Logistic regression was used to calculate the odds ratio between a risk category (inclusion criteria for risk category described in "independent variables" section) and an adverse neonatal outcome, with parity 1-2/age 18$<35$ women as reference. In addition to unadjusted analysis, available socioeconomic and maternal nutritional variables were placed in the model to determine if they confounded the association [See Supplemental Table 1 in Additional file 1 for the list of covariates adjusted for during analyses]. Odds ratios, instead of relative risks, were used, due to convergence issues in adjusted analysis. The datasets were not pooled, as each dataset contained a different set of possible confounders. Not all studies reported an association for each exposure and outcome due to low prevalence in their respective studies. Once the associations were calculated at the study level, they were meta-analyzed using the metan command in Stata. Random effects models were used to address heterogeneity across studies.

We also conducted sensitivity analyses to explore the risk of more extreme cut-offs of parity and maternal age than what DHS presently defines as high risk, using the ten datasets available to the primary author. We examined the impact of higher parity and younger age by comparing the following adjusted odds ratios (aOR): 1 ) higher parity: parity $\geq 5$ /age $18-<35$ versus parity $\geq 3$ /age $18-<35,2)$ higher parity among high age women: parity $\geq 5$ /age $\geq 35$ versus parity $\geq 3$ /age $\geq 35$, and 3 ) younger age among nulliparous women: nulliparous/age $<16$ versus nulliparous/age $<18$. For all of these aORs, the reference group remained parity $1-2$ /age $18-<35$. No analysis was conducted to examine parity $1-2$ /age $<16$ because of the small sample size across all studies in this exposure category.

We considered an alpha value of 0.05 to be statistically significant and all tests were two-sided. We used Stata 12.0 (StataCorp. 2009. College Station, TX: StataCorp LP) for analysis.

\section{Results}

Distribution of parity-age exposure in study populations

Table 2 presents the median and range of prevalence for each parity/age risk category across all 14 studies. The reference parity $1-2$ /age $18-<35$ category had a median prevalence of $39.9 \%$ (range: $33.3-51.5 \%$ ). Four other categories had at least seven of the 14 studies with prevalence over $5 \%$ in the respective categories. All 14 studies reported a prevalence of over $5 \%$ for nulliparous/ age $18-<35$ and parity $\geq 3$ /age $18-<35$, with median prevalence of $28.3 \%$ and $13.4 \%$ respectively. The nulliparous/age $<18$ and parity $\geq 3$ /age $\geq 35$ categories both had at least seven studies reporting over $5 \%$ prevalence. The analyses were only conducted for these four risk categories.

\section{Prevalence of adverse neonatal outcomes in study populations}

The prevalence of adverse neonatal outcomes in each study is shown in Supplemental Table 2 in Additional file 1. SGA prevalence was generally lowest in Latin America (range: 10.8-21.1\%) and highest in Asia, particularly South Asia (South Asia range: 52.3-61.5\%). Preterm prevalence followed a similar regional pattern. Neonatal mortality rates were highest in South Asia (highest rate: 42 per 1000 live births in Nepal), but infant mortality rates were comparable for the South Asian and African studies, with Latin America having the lowest rates of neonatal and infant mortality.

\section{Associations between parity-age exposure categories and outcomes}

In nearly all cases for SGA, preterm, and mortality outcomes, inclusion of socioeconomic and maternal nutrition variables did not alter the effect sizes by more than $10 \%$ (unadjusted ORs not presented). In cases where the effect size differed by more than $10 \%$, the $95 \%$ confidence intervals $(\mathrm{CI})$ overlapped.

We report the meta-analyzed associations below. The reference parity/age category is parity $1-2$ /age $18-<35$ for all analyses.

\section{SGA}

Nulliparous/age $<18$ had a statistically significant adverse association with SGA (see Table 3). Both nulliparous/age $<18$ (aOR: 1.80, 95\% CI: 1.62-2.01) and 
Table 3 Adjusted odds ratios for adverse outcomes, by reproductive health risk factor categories

\begin{tabular}{|c|c|c|c|c|c|c|c|c|c|c|c|c|}
\hline \multirow[b]{2}{*}{ Outcome } & \multicolumn{3}{|c|}{ Nulliparous / Age <18 } & \multicolumn{3}{|c|}{ Nulliparous / Age 18-<35 } & \multicolumn{3}{|c|}{ Parity $\geq 3$ / Age $18-<35$} & \multicolumn{3}{|c|}{ Parity $\geq 3$ / Age $\geq 35$} \\
\hline & $\mathrm{N}^{*}$ & $\mathrm{aOR}$ & $95 \% \mathrm{Cl}$ & $\mathrm{N}^{*}$ & aOR & $95 \% \mathrm{Cl}$ & $\mathrm{N}^{*}$ & $\mathrm{aOR}$ & $95 \% \mathrm{Cl}$ & $\mathrm{N}^{*}$ & aOR & $95 \% \mathrm{Cl}$ \\
\hline SGA (reference: AGA) & 14 & 1.80 & $1.62,2.01$ & 14 & 1.51 & $1.39,1.64$ & 14 & 0.92 & $0.86,0.99$ & 13 & 0.98 & $0.87,1.09$ \\
\hline Preterm (reference: term) & 14 & 1.52 & $1.40,1.66$ & 14 & 1.09 & $0.99,1.21$ & 14 & 1.20 & $1.06,1.35$ & 12 & 1.43 & $1.21,1.69$ \\
\hline Term-SGA (reference: term-AGA) & 14 & 1.81 & $1.51,2.16$ & 14 & 1.64 & $1.46,1.85$ & 14 & 0.88 & $0.81,0.96$ & 13 & 1.06 & $0.93,1.20$ \\
\hline Preterm-AGA (reference: term-AGA) & 13 & 1.75 & $1.56,1.98$ & 13 & 1.30 & $1.09,1.54$ & 13 & 1.13 & $0.98,1.30$ & 12 & 1.39 & $1.16,1.65$ \\
\hline Preterm-SGA (reference: term-AGA) & 11 & 3.14 & $2.18,4.53$ & 14 & 2.67 & $1.97,3.61$ & 13 & 1.07 & $0.83,1.38$ & 12 & 1.24 & $1.06,1.44$ \\
\hline Neonatal Mortality & 12 & 2.07 & $1.69,2.54$ & 13 & 1.28 & $1.07,1.51$ & 12 & 1.30 & $1.11,1.51$ & 10 & 1.66 & $1.23,2.23$ \\
\hline Infant Mortality & 8 & 1.49 & $1.13,1.97$ & 8 & 1.11 & $0.82,1.52$ & 8 & 1.40 & $1.04,1.89$ & 8 & 1.36 & $0.92,2.03$ \\
\hline
\end{tabular}

* $\mathrm{N}=$ number of studies included in the meta-analysis

Controlled for socioeconomic and maternal nutritional variables from Supplemental Table 1 in Additional file 1.

Reference exposure: parity 1-2 / Age 18-<35.

$\mathrm{SGA}=$ small-for-gestational-age, defined as below the 10th percentile of the U.S. 1991 reference distribution described by Alexander and colleagues [38]. AGA = appropriate-for-gestational-age. Preterm = below 37 completed weeks of gestation.

nulliparous/age 18-<35 (aOR 1.51, 95\% CI: 1.39-1.64) had increased risk of SGA. The confidence interval for these two associations overlapped slightly. The parity $\geq 3$ /age 18- $<35$ category did not have an adverse association. Instead, we saw a small but statistically significant protective effect against SGA (aOR: 0.92, 95\% CI 0.860.99 ). The parity $\geq 3$ /age $\geq 35$ category had no significant association.

\section{Preterm}

Almost all exposure categories had statistically significant associations with preterm birth. The nulliparous/age $<18$ category had the highest risk of preterm birth (aOR: 1.52, $95 \%$ CI 1.40-1.66), followed by parity $\geq 3$ /age $\geq 35$ (aOR 1.43, 95\% CI: $1.21-1.69$ ) and parity $\geq 3 /$ age $18-<35$ (aOR: 1.20, 95\% CI: 1.06-1.35) (see Table 3).

\section{Gestational age-SGA combined categories}

Term-SGA. Nulliparous/age $<18$ mothers had a significant association with term-SGA (aOR: $1.81,95 \% \mathrm{CI}$ : 1.51-2.16). Nulliparous/age $18-<35$ had slightly weaker but significant associations. The parity $\geq 3$ /age $18-<35$ women had a significant protective association (aOR: 0.88 , 95\% CI: $0.81-0.96$ ), and parity $\geq 3$ /age $\geq 35$ had no association. Preterm-AGA. Nulliparous/age $<18$ had the largest association (aOR: 1.83, 95\% CI: 1.48-2.27). Nulliparous/age $18-<35$ and parity $\geq 3$ /age $\geq 35$ had $30-40 \%$ significant increase in odds, and parity $\geq 3$ /age $18-<35$ had no significant association. Preterm-SGA. Nulliparous/age $<18$ mothers once again had the highest association (aOR: 3.14, 95\% CI: 2.18-4.53), followed by nulliparous/age 18-<35 (aOR: 2.67, 95\% CI: 1.97-3.61). Parity $\geq 3$ /age $\geq 35$ had slightly increased odds (aOR: $1.24,95 \%$ CI: $1.06-1.44)$, and parity $\geq 3$ /age $18-<35$ had no association. (See Table 3 and Figure 1). Relative risks (RR) were requested for use in $L i S T$, and the unadjusted RRs can be found in Supplemental Table 3 in Additional file 1 .

\section{Neonatal and infant mortality}

All datasets contributed systematic neonatal mortality data except Peru (very low incidence). All risk categories had statistically significant increased odds of neonatal mortality, but the magnitude of the effect size varied. Nulliparous/age $<18$ had an approximately two-fold increased risk (aOR: 2.07, 95\% CI 1.69-2.54). Nulliparous/age $18-<35$ had a $28 \%$ increase in odds $(95 \% \mathrm{CI}$, $1.07-1.51$ ), parity $\geq 3$ /age $18-<35$ had a $30 \%$ increase in odds (95\% CI: 1.11-1.51), and parity $\geq 3$ /age $\geq 35$ had a $66 \%$ increase in odds (95\% CI: $1.23-2.23$ ). We had fewer studies contributing infant mortality, as five of the datasets did not follow children systematically up to one year. For infant mortality, the statistically significant association only remained for nulliparous/age $<18$ (aOR $1.49,95 \%$ CI $1.13-1.97$ ) and parity $\geq 3$ /age $18-<35$ (aOR 1.40, 95\% CI 1.04-1.89) (See Table 3).

\section{Examining higher parity and lower age cut-offs}

Higher parity and lower age cut-offs were examined for the ten datasets available to the primary author. When increasing the parity cut-off to 5 , we did not notice large differences in odds ratios. For both parity $\geq 5$ /age $18-<35$ and parity $\geq 5 /$ age $\geq 35$, the magnitude of all the associations were very similar to parity cut-off of 3 . For nulliparous/age $<16$, we saw a consistent increase in odds ratios compared to nulliparous/age $<18$, particularly for preterm outcomes. However, none of the associations were statistically significantly different between the two exposure categories (Supplemental Table 4a-c in Additional file 1).

\section{Discussion}

Our analyses found associations with adverse neonatal outcomes for some reproductive characteristics previously considered high risk, while not for others. Nulliparous women had significant associations with adverse outcomes, but particularly when mothers were also of 


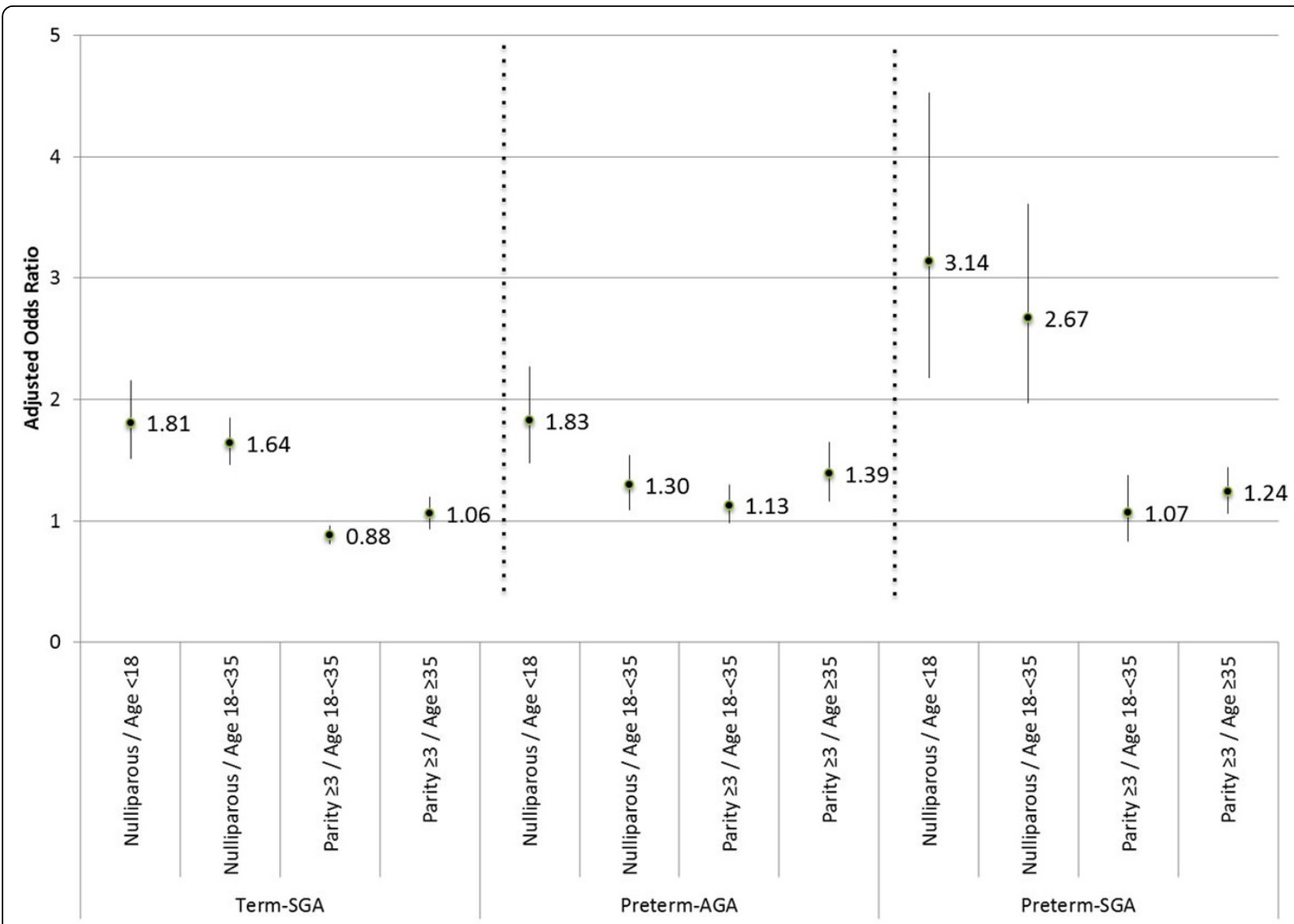

Figure 1 Adjusted odds ratios for adverse outcomes, by Term-SGA, Preterm-AGA, and Preterm-SGA (reference: Term-AGA). SGA = small-for-gestational-age, defined as below the $10^{\text {th }}$ percentile of the U.S. 1991 reference distribution described by Alexander and colleagues [38]. AGA = appropriate-for-gestational-age. Preterm = below 37 completed weeks of gestation.

young age; women who were both nulliparous and age $<18$ consistently experienced the highest risk. Young age appeared to drive preterm risk, as seen in the statistically significantly different preterm associations comparing nulliparous women age $<18$ to age $18-<35$. When we conducted sensitivity analyses using a lower age cutoff of 16, the associations increased in magnitude, particularly for preterm outcomes. Although the change in associations were not statistically significant, this may be driven by sample size, as we had a very low prevalence of women under age 16. Several studies have reported increased rates of preterm delivery and/or neonatal mortality among young mothers $[3,5,39,40]$. A plausible biological explanation may be incomplete maternal physical growth and relative malnutrition, which is related to the mother's gynecological age rather than chronological age [3]. In a U.S. study, growing adolescents accrued more fat and more weight during their pregnancy, but their infants weighed less at birth and their mothers retained more weight postpartum [41]. In resource-constrained settings, adolescent mothers may have an even larger nutritional burden; a study in rural Nepal observed lighter newborns and a larger loss of mid-upper arm circumference in pregnancy among adolescent mothers than their older counterparts [42]. The association with young age may also be related to women taking two years post-menarche or longer to reach their adult stature and pelvic dimensions [43]. We did not have data on gynecological age to explore this issue.

For age $\geq 35$, we witnessed an increase in risk of preterm birth, but no association with SGA. The preterm association may be attributed to greater incidence of chromosomal or congenital abnormalities, or confounding by maternal morbidities such as gestational diabetes, pre-eclampsia, and hypertension, as well as chronic disease, which may be more common among older mothers $[9,44]$. Previous studies link advanced maternal age to increased risk of preterm delivery and poor perinatal outcomes, with age having a dose response relationship to risk $[9,45]$. There were not enough women in our data with advanced age to explore a possible dose response relationship of age beyond 35 . 
Our analysis yielded mixed results on the association between parity $\geq 3$ and adverse outcomes. We saw no adverse association with SGA, and a weak association with preterm. WWhen we conducted sensitivity analyses by raising the parity cut-off to $\geq 5$, we saw no dose response relationship, which puts into question an actual biological association between high parity and adverse newborn outcomes. This hypothesis is supported by some previous literature. A separate analysis in this supplement using DHS datasets [46] noted that the increased mortality risk among high parity infants was attributable mostly, if not entirely, to confounders strongly correlated with the mother having high fertility at the end of her reproductive period. A series of studies from Israel also attributed higher rates of negative outcomes to socioeconomic and environmental factors highly correlated with high parity $[10,47,48]$. Finally, several studies have reported that grand multiparous women had no increased risk in contexts where women were economically stable or had proper access to care [49-51]. In light of these findings, we believe that residual confounding, and not biological mechanisms, may fully account for the association between high parity and adverse outcomes. It is unclear why we see a slight, but significant protective association between parity $\geq 3$ and SGA. With the parity $\geq 5$ cut-off, the magnitude of the associations remained almost identical, although the associations lost statistical significance. The lack of change in risk with increasing parity may again hint that confounders not captured by the covariates in our data are at play.

All risk categories had a statistically significant association with neonatal mortality, with age $<18$ and age $\geq 35$ appearing to be the largest drivers of mortality. Only nulliparous/age $<18$ and parity $\geq 3 /$ age $18-<35$ retained statistically significant associations with infant mortality. The parity and age risks may be operating on mortality through SGA/preterm and/or confounders like socioeconomic characteristics or access to care that may not have been fully captured by the available control variables.

An increase in contraceptive prevalence has been effective in reducing high parity and advanced age births, but not in delaying maternal age at first birth. Stover and Ross report an extremely low correlation of $R^{2}=0.05$ between contraceptive prevalence rate and percentage of births with mothers age $<18$ years [52]. This implies the need to focus on addressing adolescent pregnancies and for innovative strategies that may be more successful in delaying age at first birth. This may mean expanding the scope of interventions beyond the health sector; for instance, some literature suggests that educational attainment delays age to first birth [53-55]. In finding effective interventions, it is also important to understand factors beyond knowledge and access that motivate reproductive decisions. For instance, survival of previous children and desired family size could be driving higher age and parity births, and depending on the circumstances, ensuring child survival may be more effective in addressing reproductive risk than family planning. Finally, there is a need to address the equity issues surrounding access to family planning. There are substantial gaps in contraceptive prevalence between women belonging to high wealth quintiles and to low wealth quintiles [56,57]. Those who have the least access are most likely the ones who need it the most, as suggested by our concerns with residual confounding.

The strength of our analyses is the use of high quality, population-based cohort data that allows us to make better inferences of causation. We have examined how parity and maternal age together may impact outcome, rather than simply using one or the other as a control variable. We were also able to use standardized definitions for both exposures and outcomes, enhancing comparability across studies. Previous studies have used a variety of cut-offs and definitions for parity and age $[3,4,15,16]$. Taking SGA as an example, even using the most widely accepted definition (under $10^{\text {th }}$ percentile of a reference distribution), the prevalence of SGA can vary depending on which reference distribution is being used. SGA prevalence ranged from $5-72 \%$ when applying existing reference distributions to a single population sample (Joanne Katz, personal communication).

A weakness of our study is the limit of confounders available in each primary study. We controlled for the available confounders, but there still remains the possibility of residual confounding. In addition to our aforementioned discussion on high parity and residual confounding, there is also literature suggesting that controlling for socioeconomic characteristics largely attenuates the risk of adverse outcomes with young maternal age $[58,59]$. Although there is strong evidence for biological mechanisms linking nulliparity to adverse outcomes, those associations may also still be partially confounded by factors like quality and/or access to health care. Birth interval is another reproductive factor that could be a confounder, but was not included in this analysis, as a majority of the studies did not have that information. A separate study in this supplement evaluates the associations between birth intervals and poor outcomes, controlling for parity and maternal age in a subset of our datasets with relevant information [60]. Variables like survival of previous children may reflect underlying maternal health and socioeconomic conditions that are not well captured in the available variables.

Due to limitations of the data, we were not able to explore gravidity (all pregnancies), instead of parity (all live births), as the exposure. Using gravidity instead may have given us additional insight into the mechanisms linking parity and birth outcome; particularly with stillbirths 
and less so with miscarriages, we would expect mothers to endure similar nutritional demand during pregnancy as a live birth. Furthermore, by not taking into account miscarriages and stillbirths as outcomes, we may be underestimating the negative impact of some of the risk factors. There is existing literature that links nulliparity with stillbirth and intrapartum-related neonatal mortality $[6,61,62]$. A systematic review showed increased risk of stillbirth and perinatal death with older maternal age [63]. In contrast, publications have produced mixed findings pertaining to the associations between high parity and stillbirth $[6,64]$ as well as young maternal age and stillbirth [3]. Collecting more detailed information may help us better understand the mechanisms linking reproductive health risk factors to adverse fetal and perinatal outcomes, and support betterdesigned and better-timed interventions for at-risk mothers and newborns.

Although the studies included in our analyses are all population-based studies, we acknowledge that the data are not nationally representative. However, we believe that the risk associations we present here are less likely to be influenced by this, as prevalence estimates may be. Finally, we were only able to conduct sensitivity analyses of the parity $\geq 5$ and age $<16$ years cut-offs on the datasets available to the primary author and with high enough prevalence in the respective categories.

\section{Conclusions}

The highest odds of adverse neonatal outcomes associated with nulliparous/age $<18$ mothers and also the increased odds seen among parity $\geq 3$ /age $\geq 35$ mothers indicate that reproductive health interventions and education need to occur throughout a woman's reproductive period. Delaying maternal age at first birth could decrease risk for all adverse neonatal outcomes, but family planning interventions appear to be the least successful in addressing this risk factor. This calls upon family planning experts to refocus their efforts on finding interventions that will more effectively address this issue.

For LiST, we recommend including no association between high parity and adverse newborn outcomes. We recommend including the associations presented here for nulliparity, age $<18$ years, and age $\geq 35$ years, with the caveat that the associations may still be influenced by residual confounding.

\section{Additional material}

Additional file 1: Supplemental material.

Competing interests

We report no competing interests.

\section{Authors' contributions}

NK was responsible for study design, data collection, literature review, analyses of primary datasets and the meta-analyses, and writing of the manuscript. ACL and JK were responsible for study design, data collection, interpretation of results, and helped draft the manuscript.

MFS, AS, JPV helped analyze primary datasets and reviewed the manuscript FB, LC, PC, WF, JH, LH, AM, RN, DO, DR, JT, and AV contributed data and reviewed the manuscript. REB contributed to study design and interpretation of results, and reviewed the manuscript. All authors read and approved the final manuscript.

\section{Acknowledgements}

We would like to thank Neff Walker for his invaluable contributions to the study design, interpretation of findings, and to the writing of a manuscript, and the CHERG SGA-Preterm Birth working group for their feedback. The individual studies would like to acknowledge the following individuals: Ramesh Adhikari, Christian Coles, Gary Darmstadt, Sheela Devi, Subarna Khatry, Hermann Lanou, Steve LeClerq, Gernard I Msamanga, R.D. Thulariraj, Laeticia Celine Toe, Willy Urassa, Cesar G Victora, Keith West, and Nelly Zavaleta.

Funding was provided by the Bill \& Melinda Gates Foundation (810-2054) by a grant to the US Fund for UNICEF to support the activities of the Child Health Epidemiology Reference Group. Investigators were offered financial support for analysis via subcontracts by the US Fund for UNICEF. The funding sources of the individual studies are as follows: India (2000) - Center for Human Nutrition (Johns Hopkins School of Public Health), Office of Health and Nutrition (USAID), Bill and Melinda Gates Foundation (BMGF), Task Force Sight and Life; Nepal (1999) - USAID, UNICEF Country Office (Kathmandu, Nepal), BMGF; Nepal (2003) - Wellcome Trust; Nepal (2004) National Institutes of Health (NIH), BMGF, USAID, Proctor and Gamble; Philippines (1983) - NIH, Nestle's Coordinating Center for Nutritional Research, Wyeth International, Ford Foundation, US National Academy of Science, World Health Organization (WHO), Carolina Population Center, USAID; Thailand (2001) - Thailand Research Fund, Health System Research Office, Ministry of Public Health, Thailand; Burkina Faso (2004) - Nutrition Third World, Belgian Ministry of Development; Burkina Faso (2006) - Flemish University Council, Nutrition Third World, Belgian Ministry of Development, Nutriset; Tanzania (2001) - National Institute of Child Health and Human Development; Zimbabwe (1997) - Canadian International Development Agency, USAID, BMGF, Rockefeller Foundation, BASF; Brazil (1982) International Development Research Center for Canada, WHO, UK Overseas Development Administration; Brazil (1993) - UN Development Fund for Women; Brazil (2004) - Wellcome Trust; Peru (1995) - Office of Health and Nutrition (USAID). The funders played no role in the manuscript.

\section{Declarations}

The publication costs for this supplement were funded by a grant from the Bill \& Melinda Gates Foundation to the US Fund for UNICEF (grant 43386 to "Promote evidence-based decision making in designing maternal, neonatal, and child health interventions in low- and middle-income countries"). The Supplement Editor is the principle investigator and lead in the development of the Lives Saved Tool (LiST), supported by grant 43386 . He declares that he has no competing interests.

This article has been published as part of BMC Public Health Volume 13 Supplement 3, 2013: The Lives Saved Tool in 2013: new capabilities and applications. The full contents of the supplement are available online at http://www.biomedcentral.com/bmcpublichealth/supplements/13/\$3.

\section{Authors' details}

'Department of International Health, Johns Hopkins Bloomberg School of Public Health, 615 N. Wolfe St., Baltimore, MD 21205, USA. ²Brigham and Women's Hospital, 75 Francis Street, Boston, MA 02115, USA. ${ }^{3}$ Programa de Pós-graduacao em Epidemiologia, Universidade Federal de Pelotas, Rua Marechal Deodoro 1160, 30 piso, Centro, CEP 96020-220, Pelotas, RS, Brazil. ${ }^{4}$ Department of Epidemiology, Harvard School of Public Health, 677 Huntington Ave, Boston, MA 02115 USA. ${ }^{5}$ School of Population Health, Faculty of Medicine, Dentistry and Health Sciences, University of Western Australia, 35 Stirling Highway Crawley WA 6009, Perth, Australia. ${ }^{6}$ UNDP/ UNFPA/UNICEF/WHO/Word Bank Special Programme of Research, Development and Research Training in Human Reproduction (HRP) Department of Reproductive Health and Research, World Health 
Organization, Geneva, Switzerland. ${ }^{7}$ University of North Carolina School of Public Health, 135 Dauer Drive, Chapel Hill, NC 27599, USA. ${ }^{8}$ Programa de Pós-graduação em Saúde e Comportamento, Univertsidade Católica de Pelotas, Félix da Cunha, 412, CEP 96010-000, Centro, Pelotas, RS, Brazil. ${ }^{9}$ Departments of Nutrition, Epidemiology, and Global Health and Population, Harvard School of Public Health, 677 Huntington Ave, Boston, MA 02115 USA. ${ }^{10}$ Zvitambo, No 1 Borrowdale Road, Borrowdale, Harare, Zimbabwe. ${ }^{11}$ Department of Food Safety and Food Quality, Ghent University, Coupure Links 653, B - 9000, Ghent, Belgium. ${ }^{12}$ Woman and Child Health Research Center, Department of Public Health, Institute of Tropical Medicine Nationalestraat 155, 2000 Antwerpen, Belgium. ${ }^{13}$ ASEAN Institute for Health Development, Mahidol University, 999 Phuttamonthon 4 Rd, Salaya, Nakhon Pathom 73170, Thailand. ${ }^{14}$ Institute for Global Health, UCL Institute of Child Health, 30 Guilford Street, London WC1N 1EH, UK.

Published: 17 September 2013

\section{References}

1. Kiely $\mathrm{L}$, Paneth N, Susser M: An assessment of the effects of maternal age and parity in different components of perinatal mortality. American Journal of Epidemiology 1986, 123(3):444-454.

2. Usta IM, Zoorob D, Abu-Musa A, Naassan G, Nassar AH: Obstetric outcome of teenage pregnancies compared with adult pregnancies. Acta Obstetricia et Gynecologica Scandinavica 2008, 87(2):178-183.

3. Gibbs CM, Wendt A, Peters S, Hogue CJ: The impact of early age at first childbirth on maternal and infant health. Paediatric and Perinatal Epidemiology 2012, 26(Suppl 1):259-284.

4. Shah PS: Parity and low birth weight and preterm birth: a systematic review and meta-analyses. Acta Obstetricia et Gynecologica Scandinavica 2010, 89(7):862-875.

5. Scholl TO, Hediger ML, Huang J, Johnson FE, Smith W, Ances IG: Young maternal age and parity. Influences on pregnancy outcome. Annals of Epidemiology 1992, 2(5):565-575.

6. Lee AC, Mullany LC, Tielsch JM, Katz J, Khatry SK, LeClerq SC, Adhikari RK, Darmstadt GL: Community-based stillbirth rates and risk factors in rural Sarlahi, Nepal. Int J Gynecol Obstet 2011, 113(3):199-204.

7. Kramer KL, Lancaster JB: Teen motherhood in cross-cultural perspective. Annals of Human Biology 2010, 37(5):613-628.

8. Carolan M, Frankowska D: Advanced maternal age and adverse perinatal outcome: a review of the evidence. Midwifery 2011, 27(6):793-801.

9. Yogev Y, Melamed N, Bardin R, Tenenbaum-Gavish K, Ben-Shitrit G, BenHaroush A: Pregnancy outcome at extremely advanced maternal age. Am J Obstet Gynecol 2010, 203(6):558e.1-558-e.7.

10. Seidman DS, Gale R, Slater PE, Ever-Hadani P, Harlap S: Does grand multiparity affect fetal outcome? Int J Gynaecol Obstet 1987, 25(1):1-7.

11. Sharma V, Katz J, Mullany LC, Khatry SK, LeClerq SC, Shrestha SR, Darmstadt GL, Tielsch JM: Young maternal age and the risk of neonatal mortality in rural Nepal. Archives of Pediatrics \& Adolescent Medicine 2008, 162(9):828-835.

12. Taffa N: A comparison of pregnancy and child health outcomes between teenage and adult mothers in the slums of Nairobi, Kenya. International Journal of Adolescent Medicine and Health 2003, 15(4):321-329.

13. Finlay JE, Ozaltin $E$, Canning D: The association of maternal age with infant mortality, child anthropometric failure, diarrhoea and anaemia for first births: evidence from 55 low- and middle-income countries. BMJ Open 2011, 1(2):e000226.

14. Titaley CR, Dibley MJ, Agho K, Roberts CL, Hall J: Determinants of neonatal mortality in Indonesia. BMC Public Health 2008, 8:232.

15. National Statistical Office (Malawi), ORC Macro: Malawi Demographic and Health Survey 2004. Claverton, Maryland; 2005.

16. Grisaru-Granovsky S, Gordon ES, Haklai Z, Samueloff A, Schimmel MM: Effect of interpregnancy interval on adverse perinatal outcomes-a national study. Contraception 2009, 80(6):512-518.

17. Allen SJ, Raiko A, O'Donnell A, Alexander ND, Clegg JB: Causes of preterm delivery and intrauterine growth retardation in a malaria endemic region of Papua New Guinea. Archives of Disease in Childhood: Fetal and Neonatal Edition 1998, 79(2):F135-140.

18. Clausson B, Cnattingius S, Axelsson O: Preterm and term births of small for gestational age infants: a population-based study of risk factors among nulliparous women. British Journal of Obstetrics and Gynaecology 1998, 105(9):1011-1017.
19. Sachdev HS, Hall A: Development and use of the Lives Saved Tool (LiST): A model to estimate the impact of scaling up proven interventions on maternal, neonatal, and child mortality. In International Journal of Epidemiology Walker N 2010, i5-i205.

20. Katz J, Lee AC, Kozuki N, Lawn J, Cousens S, Blencowe H, Ezzati M, et al: Mortality risk in preterm and small-for-gestational-age infants in lowincome and middle-income countries: a pooled country analysis. Lancet 2013, 382(9890):417-425.

21. Victora CG, Barros FC: Cohort profile: the 1982 Pelotas (Brazil) birth cohort study. International Journal of Epidemiology 2006, 35(2):237-242.

22. Victora CG, Hallal PC, Araujo CL, Menezes AM, Wells JC, Barros FC: Cohort profile: the 1993 Pelotas (Brazil) birth cohort study. International Journal of Epidemiology 2008, 37(4):704-709.

23. Santos IS, Barros AJ, Matijasevich A, Domingues MR, Barros FC, Victora CG Cohort profile: the 2004 Pelotas (Brazil) birth cohort study. International Journal of Epidemiology 2011, 40(6):1461-1468.

24. Caulfield LE, Zavaleta N, Figueroa A, Leon Z: Maternal zinc supplementation does not affect size at birth or pregnancy duration in Peru. The Journal of Nutrition 1999, 129(8):1563-1568.

25. Rahmathullah L, Tielsch JM, Thulasiraj RD, Katz J, Coles C, Devi S, John R, Prakash K, Sadanand AV, Edwin N, et al: Impact of supplementing newborn infants with vitamin $A$ on early infant mortality: community based randomised trial in southern India. BMJ 2003, 327(7409):254.

26. Christian P, Khatry SK, Katz J, Pradhan EK, LeClerq SC, Shrestha SR, Adhikari RK, Sommer A, West KP Jr.: Effects of alternative maternal micronutrient supplements on low birth weight in rural Nepal: double blind randomised community trial. BMJ 2003, 326(7389):571.

27. Tielsch JM, Darmstadt GL, Mullany LC, Khatry SK, Katz J, LeClerq SC, Shrestha S, Adhikari R: Impact of newborn skin-cleansing with chlorhexidine on neonatal mortality in southern Nepal: a communitybased, cluster-randomized trial. Pediatrics 2007, 119(2):e330-340.

28. Osrin D, Vaidya A, Shrestha Y, Baniya RB, Manandhar DS, Adhikari RK, Filteau S, Tomkins A, Costello AM: Effects of antenatal multiple micronutrient supplementation on birthweight and gestational duration in Nepal: double-blind, randomised controlled trial. Lancet 2005, 365(9463):955-962

29. Adair LS: Low birth weight and intrauterine growth retardation in Filipino infants. Pediatrics 1989, 84(4):613-622.

30. Isaranurug S, Mo-suwan L, Choprapawon C: A population-based cohort study of effect of maternal risk factors on low birthweight in Thailand. Journal of the Medical Association of Thailand = Chotmaihet thangphaet 2007, 90(12):2559-2564.

31. Roberfroid D, Huybregts L, Lanou H, Henry MC, Meda N, Menten J, Kolsteren $P$ : Effects of maternal multiple micronutrient supplementation on fetal growth: a double-blind randomized controlled trial in rural Burkina Faso. Am J Clin Nutr 2008, 88(5):1330-1340.

32. Fawzi WW, Msamanga GI, Urassa W, Hertzmark E, Petraro P, Willett WC, Spiegelman D: Vitamins and perinatal outcomes among HIV-negative women in Tanzania. The New England Journal of Medicine 2007, 356(14):1423-1431.

33. Malaba LC, lliff PJ, Nathoo KJ, Marinda E, Moulton LH, Zijenah LS, Zvandasara P, Ward BJ, Humphrey JH: Effect of postpartum maternal or neonatal vitamin A supplementation on infant mortality among infants born to HIV-negative mothers in Zimbabwe. The American Journal of Clinical Nutrition 2005, 81(2):454-460.

34. Huybregts L, Roberfroid D, Lanou H, Menten J, Meda N, Van Camp J, Kolsteren P: Prenatal food supplementation fortified with multiple micronutrients increases birth length: a randomized controlled trial in rural Burkina Faso. The American Journal of Clinical Nutrition 2009, 90(6):1593-1600

35. Humphrey JH, Hargrove JW, Malaba LC, lliff PJ, Moulton LH, Mutasa K Zvandasara P, Nathoo KJ, Mzengeza F, Chidawanyika H, et al: HIV incidence among post-partum women in Zimbabwe: risk factors and the effect of vitamin A supplementation. AIDS 2006, 20(10):1437-1446.

36. Ministry of Health (Guyana) GRPA, ORC Macro: Guyana HIV/AIDS Indicator Survey 2005. Calverton; 2006

37. El-Zanaty F, Way A: Egypt Demographic and Health Survey 2008. Cairo; Ministry of Health, El-Zanaty and Associates, and Macro International 2009

38. Alexander GR, Himes JH, Kaufman RB, Mor J, Kogan M: A United States national reference for fetal growth. Obstetrics and Gynecology 1996, 87(2):163-168. 
39. Conde-Agudelo A, Belizan JM, Lammers C: Maternal-perinatal morbidity and mortality associated with adolescent pregnancy in Latin America: Cross-sectional study. American Journal of Obstetrics and Gynecology 2005, 192(2):342-349.

40. Chen XK, Wen SW, Fleming N, Demissie K, Rhoads GG, Walker M: Teenage pregnancy and adverse birth outcomes: a large population based retrospective cohort study. International Journal of Epidemiology 2007, 36(2):368-373.

41. Scholl TO, Hediger ML, Schall Jl, Khoo CS, Fischer RL: Maternal growth during pregnancy and the competition for nutrients. The American Journal of Clinical Nutrition 1994, 60(2):183-188

42. Katz J, Khatry SK, LeClerq SC, West KP, Christian P: The post-partum midupper arm circumference of adolescents is reduced by pregnancy in rural Nepal. Maternal \& Child Nutrition 2010, 6(3):287-295.

43. Moerman ML: Growth of the birth canal in adolescent girls. American Journal of Obstetrics and Gynecology 1982, 143(5):528-532.

44. Weerasekera DS, Udugama SG: Pregnancy at 40 and over: a case-control study in a developing country. J Obstet Gynaecol 2003, 23(6):625-627.

45. Cleary-Goldman J, Malone FD, Vidaver J, Ball RH, Nyberg DA, Comstock CH, Saade GR, Eddleman KA, Klugman S, Dugoff $L$, et al: Impact of maternal age on obstetric outcome. Obstetrics and Gynecology 2005 105(5 Pt 1):983-990.

46. Kozuki N, Sonneveldt E, Walker N: Residual confounding explains the association between high parity and child mortality. BMC Public Health 2013, 13(Suppl 3):S5.

47. Mor-Yosef S, Seidman DS, Samueloff A, Schenker JG: The effects of the socioeconomic status on the perinatal outcome of grand multipara. European Journal of Obstetrics, Gynecology, and Reproductive Biology 1990, 36(1-2):117-123.

48. Seidman DS, Dollberg S, Stevenson DK, Gale R: The effects of high parity and socioeconomic status on obstetric and neonatal outcome. Archives of Gynecology and Obstetrics 1991, 249(3):119-127.

49. Kumari AS, Badrinath P: Extreme grandmultiparity: is it an obstetric risk factor? European Journal of Obstetrics, Gynecology, and Reproductive Biology 2002, 101(1):22-25

50. Eidelman Al, Kamar R, Schimmel MS, Bar-On E: The grandmultipara: is she still a risk? American Journal of Obstetrics and Gynecology 1988, 158(2):389-392.

51. Hughes PF, Morrison J: Grandmultiparity-not to be feared? An analysis of grandmultiparous women receiving modern antenatal care. Int $J$ Gynaecol Obstet 1994, 44(3):211-217.

52. Stover J, Ross J: Changes in the distribution of high-risk births associated with changes in contraceptive prevalence. BMC Public Health 2013, 13(Suppl 3):S4.

53. Grindstaff CBT, Dewit D: Educational attainment, age at first birth and lifetime fertility: an analysis of Canadian fertility survey data. Canadian Review of Sociology 1991, 28(3):324-339.

54. Ferre C: Age at First Child - Does Education Delay Fertility Timing? In Policy Research Working Paper Bank TW 2009.

55. DePaoli A: Education, Teenage Fertility and Labour Market Participation Evidence from Ecuador. In Development Studies Working Papers Centro Studi Luca D'Agliano 2011.

56. World Bank: Reproductive Health at a Glance: Burkina Faso. Washington DC; 2011.

57. World Bank: Reproductive Health at a Glance: Mozambique. Washington, DC; 2011.

58. Markovitz BP, Cook R, Flick LH, Leet TL: Socioeconomic factors and adolescent pregnancy outcomes: distinctions between neonatal and post-neonatal deaths? BMC Public Health 2005, 5:79.

59. Satin AJ, Leveno KJ, Sherman ML, Reedy NJ, Lowe TW, McIntire DD: Maternal youth and pregnancy outcomes: middle school versus high school age groups compared with women beyond the teen years. American Journal of Obstetrics and Gynecology 1994, 171(1):184-187.

60. Kozuki N, Lee AC, Silveria M, Victora CG, Adair L, Humphrey J, Ntozini R, Black RE, Katz J: The associations of birth intervals with small-forgestational-age, preterm, and neonatal and infant mortality: a metaanalysis. BMC Public Health 2013, 13(Suppl 3):S3.

61. Fretts R: Stillbirth epidemiology, risk factors, and opportunities for stillbirth prevention. Clinical Obstetrics and Gynecology 2010, 53(3):588-596.
62. Kupka R, Kassaye T, Saathoff E, Hertzmark E, Msamanga Gl, Fawzi WW Predictors of stillbirth among HIV-infected Tanzanian women. Acta Obstetricia et Gynecologica Scandinavica 2009, 88(5):584-592.

63. Huang $L$, Sauve R, Birkett N, Fergusson D, van Walraven C: Maternal age and risk of stillbirth: a systematic review. CMAJ 2008, 178(2):165-172.

64. Chalumeau M, Bouvier-Colle MH, Breart G: Can clinical risk factors for late stillbirth in West Africa be detected during antenatal care or only during labour? International Journal of Epidemiology 2002, 31(3):661-668.

doi:10.1186/1471-2458-13-S3-S2

Cite this article as: Kozuki et al:: The associations of parity and maternal age with small-for-gestational-age, preterm, and neonatal and infant mortality: a meta-analysis. BMC Public Health 2013 13(Suppl 3):S2.

\section{Submit your next manuscript to BioMed Central and take full advantage of:}

- Convenient online submission

- Thorough peer review

- No space constraints or color figure charges

- Immediate publication on acceptance

- Inclusion in PubMed, CAS, Scopus and Google Scholar

- Research which is freely available for redistribution

Submit your manuscript at www.biomedcentral.com/submit
C) Biomed Central 